ఠ Open Access Full Text Article

\title{
Response to the Letter to the Editor Regarding
} "Intraclass Difference in Pneumonia Risk with Fluticasone and Budesonide in COPD:

\section{A Systematic Review of Evidence from Direct- Comparison Studies" [Response to Letter]}

\author{
Thomas P Lodise' \\ Sanjay Sethi ${ }^{2}$ \\ 'Department of Pharmacy Practice, \\ Albany College Pharmacy and Health \\ Sciences, Albany, NY, USA; ${ }^{2}$ Department \\ of Medicine, University at Buffalo Jacobs \\ School of Medicine and Biomedical \\ Sciences, Buffalo, NY, USA
}

\section{Dear editor}

We read with interest the remarks from Barnes et al regarding our recently published work (Lodise et al 2020;15:2889-2900). ${ }^{1}$ They raise some observations based on several flawed arguments that we would be glad to address in turn.

First, Barnes et al suggest that as fluticasone furoate (FF) and fluticasone propionate (FP) are molecularly distinct compounds, they should be analyzed separately. However, no head-to-head clinical trial has conclusively demonstrated a lower/different pneumonia risk with FF versus FP, and the grouping of FF and FP in our analysis is consistent with the approach taken by previous independent investigations, including by the European Medicines Agency (EMA, per the 2016 EMA Pharmacovigilance Risk Assessment Committee) and a recent meta-analysis. ${ }^{2}$

Barnes et al also seem to be missing the point that our analysis sought to compare pneumonia risks between fluticasone and budesonide using data from direct-comparison studies only. To our knowledge, our analysis is the first systematic review of direct treatment comparison studies that addresses an evidence gap highlighted in the 2016 EMA assessment. Notably, the 2016 EMA assessment could not account for some important newer publications, including 2 cohort studies, ${ }^{3,4}$ a nested case-control study, ${ }^{5}$ and a meta-analysis, ${ }^{2}$ as well as the FULFIL trial ${ }^{6}$ and a post-hoc analysis of the UPLIFT trial. ${ }^{7}$ Our inclusion of only direct-comparison studies surmounted many of the limitations associated with previous evaluations that made indirect comparisons of randomized clinical trials. In each of the direct-comparison studies included in our systematic review, treatment groups were highly similar at baseline, mitigating the impact of confounding factors on the observed results. The findings of our analysis are corroborated by numerous long-term population-based cohort and nested case-control studies conducted in several countries across multiple regions, ${ }^{3-5,8-12}$ which, taken together, reported either higher pneumonia risk or higher odds of pneumonia, depending on the study design, with fluticasone- versus budesonide-containing therapy.
Correspondence: Sanjay Sethi Clinical and Translational Research Center, 875 Ellicott St., Room 6045A, Buffalo, NY, I4215, USA

Email ssethi@buffalo.edu 
Additionally, Barnes et al voice some concerns about data inclusion. For instance, we incorporated partial data from the FULFIL study, ${ }^{6}$ excluding the (lack of a difference in) pneumonia rates at 52 weeks. This is correct, as the 52-week data were not included because the safety extension population (EXT) included only 430 out of 1,810 subjects from the intent-to-treat (ITT) population, representing a reduction of $>75 \%$ of the randomized set. This large difference between the ITT and EXT populations limits meaningful interpretations of the pneumonia-related safety data up to 52 weeks. In addition, event rates, which account for individual patient exposure/multiple events per patient and are therefore commonly used by regulatory authorities to compare safety risks between interventions, are not publicly available for that EXT population. Their letter further cites similar percentages of pneumonia in the ETHOS ${ }^{13}$ and IMPACT ${ }^{14}$ studies as evidence against an intraclass difference in pneumonia risk among inhaled corticosteroid (ICS) agents. However, this represents an indirect comparison with ICS- and non-ICScontaining treatments that was not relevant to our analysis. Notably, a closer comparison of the ETHOS and IMPACT studies still shows that the incidence and event rates for pneumonia were higher with fluticasone- versus budesonidecontaining therapy (Table 1).

Barnes et al further refer to the observational PATHOS $^{10}$ study and its associated limitations and emphasize that our findings are highly dependent on this study. As previously described, however, our conclusions were based on the totality of evidence that the difference in pneumonia risk between fluticasone and budesonide observed in FULFIL, a direct-comparison randomized trial, is corroborated by similar findings across a variety of observational studies and is consistent with a large body of evidence. In addition, in our article, we have acknowledged the limitations of observational studies and note that these limitations, including unmeasured confounders, misclassification of exposures and outcomes, and a lack of lung function data mentioned specifically in their letter, should equally apply to patients receiving fluticasone and budesonide. Furthermore, while systematic errors are always a concern in observational studies, it is important to note that the two treatment groups were extremely well balanced at baseline after matching in the PATHOS study. Therefore, the concerns raised by Barnes et al regarding potential biases present in this article are overstated.

In conclusion, we believe our systematic review represents the totality of current evidence indicating a clinically important intraclass difference in the risk of pneumonia between fluticasone- and budesonide-containing inhaled medications for chronic obstructive pulmonary disease. We hope that our clarifications will be helpful to the readership.

\section{Disclosure}

Thomas P. Lodise is a consultant for AstraZeneca. Sanjay Sethi has received research funding (to Jacobs School of Medicine, University at Buffalo, State University of New York) from Cipla, Sanofi, and GlaxoSmithKline; has been a consultant and/or participated in advisory boards for AstraZeneca, Boehringer Ingelheim, Circassia, Gilead, GlaxoSmithKline, Merck, Nabriva, Novavax, Paratek, Sunovion, and Theravance; has been a consultant for Aradigm and Pulmonx; and has been a speaker for AstraZeneca, Boehringer Ingelheim, and GlaxoSmithKline. He has received royalties from UpToDate and Taylor \& Francis. The authors would like to thank Jingyi Li, Hitesh N. Gandhi, and Gerald O'Brien for their contribution to the data analysis and interpretation. Editorial support (in the form of collating author comments, grammatical editing, and referencing) was provided by Katie Gersh, of Cello Health Communications/MedErgy (Yardley, PA, USA), in

Table I Indirect Comparison of Pneumonia Incidence Rates and Event Rates in the ETHOS and IMPACT Studies

\begin{tabular}{|c|c|c|}
\hline Treatment & Incidence Rate (\% of Patients) & Event Rate (per 1000 Patient-Years) \\
\hline Budesonide $(320 \mu \mathrm{g}) / \mathrm{glycopyrrolate/formoterol} \mathrm{fumarate}{ }^{13}$ & 4.6 & 53.3 \\
\hline Glycopyrrolate/formoterol fumarate ${ }^{13}$ & 2.9 & 37.3 \\
\hline Rate ratio & 1.6 & 1.4 \\
\hline Fluticasone furoate/umeclidinium/vilanterol ${ }^{14}$ & 8 & 95.8 \\
\hline Umeclidinium/vilanterol $^{14}$ & 5 & 61.2 \\
\hline Rate ratio & 1.6 & 1.6 \\
\hline
\end{tabular}

Note: The bolded values in the table are the rate ratios of the event rates in the ETHOS and IMPACT studies, respectively. 
accordance with Good Publication Practice (GPP3) guidelines and was funded by AstraZeneca (Wilmington, DE, USA).

\section{References}

1. Lodise TP, Li J, Gandhi HN, O’Brien G, Sethi S. Intraclass difference in pneumonia risk with fluticasone and budesonide in COPD: a systematic review of evidence from direct-comparison studies. Int J Chron Obstruct Pulmon Dis. 2020;15:2889-2900. doi:10.2147/ COPD.S269637

2. Yang M, Du Y, Chen H, Jiang D, Xu Z. Inhaled corticosteroids and risk of pneumonia in patients with chronic obstructive pulmonary disease: a meta-analysis of randomized controlled trials. Int Immunopharmacol. 2019;77:105950. doi:10.1016/j.intimp.2019.105950

3. Hirano R, Fujita M, Matsumoto T, On R, Watanabe K. Inhaled corticosteroids might not increase the risk of pneumonia in patients with chronic obstructive pulmonary disease in Japan. Int J Chron Obstruct Pulmon Dis. 2018;13:3503-3509. doi:10.2147/COPD.S180349

4. Yang HH, Lai CC, Wang YH, et al. Severe exacerbation and pneumonia in COPD patients treated with fixed combinations of inhaled corticosteroid and long-acting $\beta_{2}$ agonist. Int $J$ Chron Obstruct Pulmon Dis. 2017;12:2477-2485. doi:10.2147/COPD.S139035

5. Wang CY, Lai CC, Yang WC, et al. The association between inhaled corticosteroid and pneumonia in COPD patients: the improvement of patients' life quality with COPD in Taiwan (IMPACT) study. Int J Chron Obstruct Pulmon Dis. 2016;11:2775-2783. doi:10.2147/ COPD.S116750

6. Lipson DA, Barnacle H, Birk R, et al. FULFIL trial: once-daily triple therapy for patients with chronic obstructive pulmonary disease. $\mathrm{Am}$ $J$ Respir Crit Care Med. 2017;196(4):438-446. doi:10.1164 rccm.201703-04490C
7. Morjaria JB, Rigby A, Morice AH. Inhaled corticosteroid use and the risk of pneumonia and COPD exacerbations in the UPLIFT study. Lung. 2017;195(3):281-288. doi:10.1007/s00408-017-9990-8

8. Suissa S, Patenaude V, Lapi F, Ernst P. Inhaled corticosteroids in COPD and the risk of serious pneumonia. Thorax. 2013;68 (11):1029-1036. doi:10.1136/thoraxjnl-2012-202872

9. Suissa S, Coulombe J, Ernst P. Discontinuation of inhaled corticosteroids in COPD and the risk reduction of pneumonia. Chest. 2015;148(5):1177-1183. doi:10.1378/chest.15-0627

10. Janson C, Larsson K, Lisspers KH, et al. Pneumonia and pneumonia related mortality in patients with COPD treated with fixed combinations of inhaled corticosteroid and long acting $\beta_{2}$ agonist: observational matched cohort study (PATHOS). BMJ. 2013;346: 3306. doi:10.1136/bmj.f3306

11. Roberts M, Mapel D, Petersen H, Blanchette C, Ramachandran S. Comparative effectiveness of budesonide/formoterol and fluticasone/ salmeterol for COPD management. $J$ Med Econ. 2011;14 (6):769-776. doi:10.3111/13696998.2011.622817

12. Kern DM, Davis J, Williams SA, et al. Comparative effectiveness of budesonide/formoterol combination and fluticasone/salmeterol combination among chronic obstructive pulmonary disease patients new to controller treatment: a US administrative claims database study. Respir Res. 2015;16(1):52. doi:10.1186/s12931-015-0210-x

13. Rabe KF, Martinez FJ, Ferguson GT, et al. Triple inhaled therapy at two glucocorticoid doses in moderate-to-very-severe COPD. $N$ Engl J Med. 2020;383(1):35-48. doi:10.1056/NEJMoa1916046

14. Lipson DA, Barnhart F, Brealey N, et al. Once-daily single-inhaler triple versus dual therapy in patients with COPD. $N$ Engl $J$ Med. 2018;378(18):1671-1680. doi:10.1056/NEJMoa1713901

Dove Medical Press encourages responsible, free and frank academic debate. The content of the International Journal of Chronic Obstructive Pulmonary Disease 'letters to the editor' section does not necessarily represent the views of Dove Medical Press, its officers, agents, employees, related entities or the International Journal of Chronic Obstructive Pulmonary Disease editors. While all reasonable steps have been taken to confirm the content of each letter, Dove Medical Press accepts no liability in respect of the content of any letter, nor is it responsible for the content and accuracy of any letter to the editor.

International Journal of Chronic Obstructive Pulmonary Disease

Dovepress

\section{Publish your work in this journal}

The International Journal of COPD is an international, peer-reviewed journal of therapeutics and pharmacology focusing on concise rapid reporting of clinical studies and reviews in COPD. Special focus is given to the pathophysiological processes underlying the disease, intervention programs, patient focused education, and self management protocols. This journal is indexed on PubMed Central, MedLine and CAS. The manuscript management system is completely online and includes a very quick and fair peer-review system, which is all easy to use. Visit http://www.dovepress.com/testimonials.php to read real quotes from published authors. 